\title{
AS PRÁTICAS DOCENTES NA CONSTRUÇÃO DA LEITURA E ESCRITA NOS ANOS INICIAIS
}

\author{
Wagna Silva Souza ${ }^{1}$
}

\section{RESUMO}

Este artigo consiste numa pesquisa bibliográfica e de campo, que objetiva analisar a prática pedagógica relacionando-a com o processo de aprendizagem da linguagem escrita no contexto dos anos Iniciais do Ensino Fundamental. As reflexões de diversos autores sobre o tema alfabetização serviram de referência para a concretização deste trabalho, que tem como foco principal a necessidade de uma adequação do trabalho pedagógico à realidade do educando, como forma de se obter melhores resultados na aprendizagem dos mesmos. Buscaram-se estudos sobre o desenvolvimento do processo de aprendizagem da linguagem escrita antes da inserção da criança no ensino formal e a forma como este processo deve ser conduzido no trabalho alfabetizador, afim de que todas as crianças sejam alfabetizadas na idade certa, contribuindo desta forma para a evolução da educação e de todos os indivíduos.

Palavras - chave: Ensino Fundamental; Alfabetização; Educação.

\begin{abstract}
This article is a bibliographical and field research that aims to analyze the pedagogical practice relating it to the learning process of written language in the context of the Early Years of Elementary School. The reflections of several authors on the topic of literacy served as a reference for the accomplishment of this work, whose main focus is the need to adapt the pedagogical work to the reality of the learner, as a way to obtain better learning outcomes. Studies on the development of the learning process of written language before the insertion of the child in formal education and the way in which this process should be conducted in the literacy work were studied, so that all children are literate at the right age, thus contributing For the evolution of education and for all individuals.
\end{abstract}

Key - words: Elementary School; Literacy; Education.

\section{INTRODUÇÃO}

O desenvolvimento deste trabalho é fruto de uma pesquisa bibliográfica que pretende refletir sobre a prática alfabetizadora dos anos iniciais do ensino fundamental e analisar como é desenvolvido o processo ensino-aprendizagem da linguagem escrita. Através da pesquisa de campo, buscou-se identificar problemas inerentes ao trabalho realizado pelo docente, tendo como hipótese a solução do problema do baixo índice do rendimento escolar. Por meio dos conhecimentos teóricos obtidos pela pesquisa bibliográfica, conhece-se como se desenvolve a

\footnotetext{
1 Bacharel em Ciências Econômica pela União de Escolas de Ensino Superior Capixaba - UNESC e Licenciatura Plena em Matemática pela Universidade de Uberaba - UNIUBE. Pós-graduada e Matemática pelas Faculdades Integradas de Jacarepaguá - FIJ, Pós-graduada em Gestão Escolar Integrada: Supervisão, Orientação e Inspeção Escolar pela Universidade Castelo Branco - UCB e Pós-graduada em Educação Profissional Integrada à Educação Básica na Modalidade EJA pelo Instituto Federal Educação, Ciências e Tecnologia do Espírito Santo - IFES. E-mail: wagnassouza@ hotmail.com.
} 
aprendizagem da leitura e da escrita e a forma como a escola deve trabalhar este processo, visando o aperfeiçoamento da prática pedagógica.

Partindo da concepção de que a aprendizagem da linguagem escrita é um processo em longo prazo que se inicia antes da criança ser inserida no ambiente escolar e que através do trabalho realizado pelo docente, pode ser aproveitada para alfabetizá-la.

Portanto, a referida pesquisa irá conscientizar os leitores sobre a importância de uma prática educativa que priorize a alfabetização como processo de construção do conhecimento através de um trabalho diversificado com a leitura e a escrita, com o objetivo de formar cidadãos autônomos capazes de transformar a realidade.

\section{DESENVOLVIMENTO}

A alfabetização nos Anos Iniciais tem ganhado atenção dos governantes preocupados com os baixos índices de rendimento escolar dos alunos. Diante disso, tem investido na capacitação de professores com o objetivo de reverter este quadro. Portanto, para o alcance deste é necessário também o empenho dos professores em realizar um trabalho de qualidade no ensino da leitura e da escrita, visando uma aprendizagem que atenda a todos, sabendo da importância da linguagem escrita para os indivíduos. Como bem explica Feil ${ }^{2}$ (1989, p.12), enfatizando que: "[...] O trabalho só se tornará eficaz à medida que o professor questionar constantemente sua tarefa, bem como os instrumentos com que a realiza".

Portanto, o trabalho do professor será produtivo, se ele estiver disposto em mudar, repensando o modo como atua e diariamente buscando aperfeiçoamento de sua prática, através da diversificação de atividades que utiliza para ensinar e desenvolver as crianças.

O primeiro passo deve ser dado pelo professor, ele precisará mostrar uma insatisfação com a situação, e construir novas formas de pensar e agir com as mudanças que emergem no contexto da atualidade, e para isso, precisa inovar sua prática pedagógica por meio de ações concretas (CUNHA, 1996). ${ }^{3 .}$

\footnotetext{
${ }^{2}$ Graduada em Pedagogia Habilitação Orientação Educacional pela Universidade Regional do Noroeste do Estado do Rio Grande do Sul (1975) e Mestrado em Educação Brasileira, pela Universidade Federal de Santa Maria (1995). É professora titular da Universidade Regional do Noroeste do Estado do Rio Grande do Sul.

${ }^{3}$ Maria Isabel da Cunha. Possui graduação em Ciências Sociais (1968) e graduação em Pedagogia (1974) na Universidade Católica de Pelotas, mestrado em Educação pela Pontifícia Universidade Católica do Rio Grande do Sul (1979) e doutorado em Educação pela Universidade Estadual de Campinas (1988).
} 
Em busca do aperfeiçoamento pedagógico, o primeiro passo a ser tomado pelo docente é a conscientização do conhecimento que tem e do modo como atua. É preciso buscar, se atualizar, para não ficar com o conhecimento estagnado. É importante que ele queira mudar, pois não pode se conformar com esta situação. Para ser um bom profissional, o docente precisa se capacitar para enfrentar os desafios e solucionar os problemas. Ter vontade de renovar, melhorando a sua prática pedagógica e consequentemente tornar-se um profissional competente e consciente de seu papel na sociedade.

As mudanças na educação são decorrentes da necessidade da escola de se adaptar aos estilos de vida da sociedade, atendendo às suas exigências e expectativas e também da necessidade de transformar os indivíduos nos aspectos culturais e sociais, para que façam parte desta sociedade em constantes mudanças, através do acesso ao conhecimento.

Com a evolução da sociedade num mundo em constantes transformações, é preciso que a escola direcione seus objetivos na formação de indivíduos autônomos e para isso é preciso que disponibilize aos alunos os conhecimentos linguísticos. Desta forma, serão capazes de desenvolver diversos tipos de textos, interpretar, refletir e questionar sobre aqueles que utilizamos no nosso cotidiano e com isso exercer de forma plena a cidadania.

Antes de frequentar a escola a criança já faz uma leitura daquilo que observa ao seu redor, ouve histórias contadas pelos pais e começa a utilizar a escrita através de rabiscos e desenhos. Ou seja, ela inicia o processo de construção do conhecimento sobre a linguagem escrita. Como afirma Ferreiro ${ }^{4}(1992$, p.65), enfatizando que: "[...] Desde que nascem são construtoras de conhecimento". Portanto, a escola precisa dar continuidade a este processo, permitindo que a criança se expresse à sua maneira, enriquecendo com atividades diversificadas, visando a aprendizagem e não somente o ensino.

A criança chega à escola com uma vasta soma de experiências, de aprendizagens, que são ignoradas pelo professor. O que é lamentável, pois até seu ingresso à escola a criança já aprendeu inúmeras coisas (que deveriam servir como ponto de partida das atividades do professor). E aprendeu, talvez, com mais consistência já que ela aprendeu a fazer, fazendo-as (FEIL, 1989, p.12).

Antes de entrar na escola a criança já vivenciou muitas coisas e portanto seu conhecimento está enriquecido com muitas experiências, mas infelizmente isto não é

\footnotetext{
${ }^{4}$ Emília Beatriz Maria Ferreiro Schavi (Buenos Aires, 5 de maio de 1936) é uma psicóloga e pedagoga argentina, radicada no México, doutora pela Universidade de Genebra, sob a orientação de Jean Piaget.
} 
aproveitado pelo professor na alfabetização. Este saber construído na sua prática cotidiana é desconsiderado ao invés de ser utilizado na formação de sua educação.

Segundo Feil (1989, p.13 e 71), a criança mesmo não reconhecendo os símbolos do alfabeto, já "lê" o seu meio, estabelecendo relações entre significantes e significados; relacionando sons, cheiros e texturas com objetos. A criança aprendeu a "ler" o seu meio através da observação, do contato direto com este meio.

A criança observa o meio em que vive e com isso amplia o seu conhecimento e a compreensão sobre todas as coisas. Ela faz uma leitura deste meio mesmo não sabendo o alfabeto e consegue identificar o som, a textura e o cheiro dos objetos com os quais interage diariamente.

Pela presença constante das pessoas, dos animais e dos objetos, ela acaba por incorporar o significado das mesmas e, posteriormente, mesmo na ausência destes elementos, ela mantém a ideia da coisa e consegue descrevê-la e representá-la, através das ArtesPlásticas, dramatizações, histórias... Outro fator observado é que nomes de produtos, siglas que a criança vê constantemente, também são facilmente incorporados por ela (FEIL, 1989, p.71).

A criança tem capacidade para descrever um animal, um objeto ou qualquer outra coisa ou mesmo representá-los por meio de desenhos e histórias, mesmo não estando presentes. Também consegue identificar nomes de marcas, de produtos, de siglas através da visualização constante dos nomes. No início precisa ouvir o nome e ver a imagem, depois consegue reconhecer o nome somente visualizando.

Para Russo e Vian ${ }^{5}$ (1995):

A capacidade de imaginação da criança atravessa fronteiras e muitas vezes nos surpreende, tamanha é sua criatividade. Existem momentos em que, ao se expressar, ela foge de qualquer regra convencional de escrita, mas seu objetivo é tão claro que não podemos, simplesmente, frustrar sua criação. Para ela, tudo tem sentido: um sinal, uma letra, um desenho. Para nós, educadores, a análise dessa maneira de escrever pode demonstrar muito. Por isso, é importante dar à criança a oportunidade de manter diálogo simples e de se colocar perante o mundo.

Atualmente, temos claro que mais importante para criança é primeiro, expressar-se. Ela constrói um texto sem muito significado para nós, mas é capaz de "ler" exatamente a mensagem que quis passar, e mesmo palavras mal escritas, rabiscos e desenhos iniciais deixam de ser tentativas de escrita para se tornarem escritas reais. (RUSSO E VIAN, 1995, p.44)

\footnotetext{
${ }^{5}$ Ma de Fátima Russo e Mạ Inês Aguiar Vian dão uma visão geral da didática do professor nos diferentes níveis, alertando quanto aos estudos que vêm sendo realizados neste sentido e incentivando a leitura e estudo da trilogia intitulada Didática da Alfabetização-Nível Pré-Silábico, Nível Silábico, Nível Alfabético, de Esther Pillar Grossi, segundo os quis o professor deve procurar atingir os alunos de todos os níveis, desafiando-os para provocar o avanço.
} 
A criança é muito imaginativa e utiliza essa capacidade para se expressar usando sinais, desenhos e letras. O professor deve possibilitar que a criança se comunique através da escrita da forma que pretender, pois isto contribui para o seu desenvolvimento. Qualquer texto construído faz sentido para ela, pois sabe ler o que escreveu.

No processo de alfabetização a criança passa por etapas até aprender a ler e escrever, ou seja, decodificar e codificar. Mesmo assim é preciso outras habilidades como explica Ferreiro e Teberosky ${ }^{6}$ (1995, p.32), enfatizando que "[...] Entende-se como alfabetizada a criança que dominou a base alfabética do sistema de escrita, que lê com compreensão e escreve textos com sentido possíveis de serem lidos, mesmo que apresentem erros de ortografia".

De acordo com as autoras, a criança é considerada alfabetizada quando souber ler e escrever, dominando todo o código alfabético, entender o que lê e produzir textos coerentes mesmo que apresentem erros ortográficos.

Segundo Ferreiro (1993, p.18), as práticas convencionais levam, todavia que expressão escrita se confunda com a possibilidade de repetir fórmulas estereotipadas, a que se pratique uma escrita fora de contexto, sem nenhuma função comunicativa real e nem sequer com a função de preservar informação.

Nas práticas pedagógicas convencionais, se expressar por escrito é ser capaz de copiar e reproduzir fielmente a escrita, trabalhada de forma fragmentada, através de cópias de palavras e de frases, onde a criança não tem a oportunidade de se expressar, de se comunicar e de registrar seus conhecimentos.

As crianças têm muita curiosidade e vontade de aprender. Elas gostam de observar, de perguntar, de saber de todas as coisas e de compreender os acontecimentos. Ao ingressarem na escola para aprender, se deparam com atividades mecânicas e repetitivas, impostas pelo professor, que acabam desestimulando-as e fazendo com que percam o interesse em aprender. Como afirma Ferreiro (1993, p.17), enfatizando que "[...] as crianças são facilmente alfabetizáveis; foram os adultos que dificultaram o processo de alfabetização delas".

De acordo com a autora, as crianças aprendem facilmente o que lhes é ensinado. Os conhecimentos transmitidos pelo professor são internalizados pela mesma e assim vão construindo o seu conhecimento. Portanto, o que dificulta a aprendizagem destas são práticas

\footnotetext{
6 Ana Teberosky é uma das pesquisadoras mais respeitadas quando o tema é alfabetização. A Psicogênese da Língua Escrita, estudo desenvolvido por ela e por Emília Ferreiro no final dos anos 1970, trouxe novos elementos para esclarecer o processo vivido pelo aluno que está aprendendo a ler e a escrever.
} 
tradicionais aplicadas no processo de alfabetização, com atividades onde a escrita não tem nenhuma função social. É importante que a criança saiba qual a importância da escrita para as nossas vidas e a escola as prepare para utilizá-la no seu cotidiano.

A escrita pode ser concebida de duas formas muito diferentes e conforme o modo de considerá-la as consequências pedagógicas mudam drasticamente.

A escrita pode ser considerada como uma representação da linguagem ou como um código de transcrição gráfica das unidades sonoras. (...) Se a escrita é concebida como um código de transcrição, sua aprendizagem é concebida como a aquisição de uma técnica; se a escrita é concebida como um sistema de representação, sua aprendizagem se converte na apropriação de um novo objeto de conhecimento, ou seja, em uma aprendizagem conceitual (FERREIRO, 1992, p.10 e 16).

O aluno precisa compreender como a escrita é construída, portanto ela precisa ser vista como uma representação da linguagem, ou seja, podemos nos expressar, nos comunicar por meio dela.

Se a mesma for vista como um código de transcrição, onde as unidades sonoras são transcritas em unidades gráficas, esta aprendizagem não privilegia a construção do conhecimento, mas somente ao reconhecimento destas unidades.

Espera-se habitualmente que a criança possa ler antes de saber escrever por si mesma (sem copiar). Se pensarmos que o ensino da língua escrita tem por objetivo o aprendizado de um código de transcrição, é possível dissociar o ensino da leitura e da escrita enquanto aprendizagem de duas técnicas diferentes, embora complementares, mas esta diferenciação carece totalmente de sentido quando sabemos que, para a criança, trata-se de compreender o nosso sistema, realiza tanto atividades de interpretação como de produção. A própria ideia da possibilidade de dissociar as duas atividades é inerente à visão do ensino da escrita como o ensino de técnica de transcrição (FERREIRO, 1992, p. 35 e 36).

A construção da aprendizagem da leitura e da escrita ocorrem simultaneamente, pois a criança para entender o sistema de escrita, interpreta e produz ao mesmo tempo. Portanto, sendo o objetivo do ensino da língua escrita a representação da linguagem, não é possível separar o ensino da leitura e da escrita.

A escola pode contribuir de muitas maneiras para formar indivíduos não apenas alfabetizados, mas também letrados. Desde a alfabetização, apresentar uma ampla variedade de textos é favorecer um mergulho no mundo da escrita com a exploração de mil e uma possibilidades. Para Soares $^{7}$ (1998, p. 39), letramento é o resultado da ação de ensinar e

\footnotetext{
7 Magda Soares. Magda Becker Soares é professora titular emérita da Faculdade de Educação da UFMG. ... Graduada em Letras, doutora e livre-docente em Educação. É autora de diversos livros, e especialmente conhecida por seus livros didáticos de Língua portuguesa usados dos anos 1970 a 1990 .
} 
aprender as práticas sociais da leitura e escrita; é também o estado ou condição que adquire um grupo social ou um indivíduo como consequência de ter-se apropriado da escrita e de suas práticas sociais (CARVALHO, 2010, p. 15) ${ }^{8}$.

A função da escola é ensinar os alunos a ler e escrever, mas também a fazer uso social da leitura e escrita, ou seja, a escola precisa formar sujeitos letrados. Para isso, é preciso que se trabalhe com vários tipos de textos desde o início da alfabetização, preparando a criança para a vida social. Para Soares, letramento é a condição que adquiriu um grupo social ou um indivíduo por saber ler e escrever e fazer uso social desta linguagem em seu meio. Para a autora acima, alfabetizar e letrar são ações que devem estar acompanhadas, pois o aluno deve interagir com práticas sócias, e a leitura e a escrita podem proporcionar uma aprendizagem significativa e abrangente ao educando. (SOARES, 1998)

A autora propõe que na prática de alfabetização, o professor alfabetize letrando, ou seja, realize um trabalho no qual os alunos sejam ensinados a ler e escrever, ao mesmo tempo em que aprendam a função social da linguagem escrita. Desta forma, eles se tornam alfabetizados e letrados ao mesmo tempo.

$\mathrm{Na}$ visão da autora, ainda, alfabetizar apenas não basta, é preciso proporcionar ao educando um universo letrado, pois só assim, a leitura e escrita fará significado em seu meio social (SOARES, 2000).

Uma pessoa mesmo que já esteja alfabetizado, não é letrada. Ela sabe ler e escrever, mas para que seja também letrada é preciso que saiba ler e escrever e faça uso social da leitura e da escrita no seu cotidiano, ou seja, realize atividades variadas utilizando a linguagem escrita em todas as circunstâncias e situações sociais.

Portanto, para a concretização do uso social desta linguagem, é preciso que se proporcione ao aluno o desenvolvimento de várias habilidades, tais como a capacidade de ler e escrever, baseado em diferentes tipos textuais, podendo assim, ele informar e ao mesmo tempo se informar, o que gera dessa forma uma grande interação com a aprendizagem, ou seja, a principal função do trabalho do alfabetizador é conseguir que seus alunos produzam diferentes gêneros textuais nas diversas linguagens. (SOARES, 2001).

\footnotetext{
${ }^{8}$ Formada no Instituto de Educação do Rio de Janeiro em 1955, foi professora primária em escolas municipais da mesma cidade, de 1955 a 1968. É graduada em Pedagogia pela Faculdade de Educação da Universidade Federal do Rio de Janeiro (1969), mestre em Educação pela Universidade Federal do Rio de Janeiro (1977) e doutora em Ciências da Educação - Université de l'Etat a Liege, Bélgica (1987).
} 
É preciso que o aluno utilize a leitura e a escrita para obter e transmitir conhecimentos, para se relacionar com outras pessoas, para se informar dos acontecimentos, interpretando e refletindo criticamente sobre os diversos textos que circulam no nosso meio, presentes em jornais, revistas e livros, para informar outras pessoas, orientar-se por uma receita ou bula, fazer anotações como lembretes, divertir-se com uma história, para se expressar, expondo suas ideias, opiniões, sentimentos e pontos de vista e para interpretar variados textos sabendo também produzi-los.

Segundo Feil (1989, p. 64 e 65), a escola, sendo a entidade que tem a incumbência de ensinar a ler, vem definindo a leitura de um modo bastante estático e mecânico. Confunde o processo de ler em um simples reconhecimento de palavras em páginas impressas. Existe uma nítida separação entre o mecanismo da leitura e o pensamento, reduzindo a leitura a um ato mecânico de decifrar letras. A verdadeira leitura consiste na captação de significados, numa crescente comunicação entre o leitor e o texto. Implica em aprender a descobrir, reconhecer e utilizar os sinais da linguagem.

A função da escola é ensinar a ler, mas infelizmente a leitura é trabalhada de uma forma mecânica, visando somente o reconhecimento de letras e palavras. O objetivo da leitura deve ser a interação, o diálogo do leitor com o texto, a reflexão, a interpretação e o aprendizado de novos conceitos.

É preciso que a escola dê atenção especial à entrada do aluno no Ensino Fundamental, independentemente de ter frequentado a pré-escola, para que se mantenha as relações sociais e afetivas no ambiente educativo e seja educado de forma que se sinta seguro e confiante. É necessário que este contexto educativo seja contínuo e ampliado (BRASIL,2001) ${ }^{9}$.

Aos seis anos, a criança descobre e, aos poucos, aprende a utilizar as diferentes linguagens: sonoras, orais, gestuais, gráficas, musicais e principalmente a linguagem do brincar, que lhe é própria. Ela as utiliza individualmente e no relacionamento com outras crianças, sendo que esta maneira de se comunicar desenvolve-se no próprio lar e na escola.

A criança que cresce numa sociedade onde visualiza constantemente signos escritos e presencia atos de leitura e escrita, sente vontade de aprender e ingressar numa instituição

\footnotetext{
${ }^{9}$ Os Parâmetros Curriculares Nacionais constituem um referencial de qualidade para a educação no Ensino Fundamental em todo o País. Sua função é orientar e garantir a coerência dos investimentos no sistema educacional, socializando discussões, pesquisas e recomendações, subsidiando a participação de técnicos e professores brasileiros, principalmente daqueles que se encontram mais isolados, com menor contato com a produção pedagógica atual.
} 
escolar, pois sabe que neste ambiente irá se socializar e brincar com outras crianças, além de se apropriar da linguagem escrita.

\begin{abstract}
Conclui-se que é infrutífera uma discussão sobre se é possível ou não alfabetização e letramento aos 6 anos, se é conveniente ou não alfabetização e letramento na Educação Infantil; à instituição educativa cumpre dar prosseguimento ao processo de inserção da criança no mundo da escrita, a partir do estágio em que ela estiver e, em nossas sociedades grafocêntricas, ela sempre estará já em algum estágio de alfabetização e letramento (ainda que, para algumas, muito inicial) - tornando esse processo sistemático, metódico, orientado por planejamento fundamentado em princípios psicológicos, linguísticos, pedagógicos (SOARES, 2010, p. 23).
\end{abstract}

Segundo a autora, não há necessidade de haver uma discussão sobre a possibilidade de alfabetizar e letrar as crianças aos 6 anos e também se é apropriado desenvolver estes processos na Educação Infantil. Cabe à escola, ensiná-la a partir do estágio de aprendizagem em que se encontrar. Numa sociedade como a nossa, centrada na escrita, a criança ingressa na escola com conhecimentos sobre a linguagem escrita, que aprendeu em seu meio, e portanto já iniciou o processo de alfabetização e letramento. Na escola, ela precisa de um estudo mais sistemático e planejado.

A escrita não é utilizada somente na escola e portanto deve ser trabalhada dentro de um contexto significativo, para que desta forma a criança conheça as diversas situações de uso. É preciso que se trabalhe a função social da escrita, os diferentes tipos de textos, o sistema alfabético e ortográfico.

Muitas crianças que crescem em famílias de pouco respaldo econômico e que raramente fazem uso da linguagem escrita, somente terão contato com esta linguagem na escola. Esta é responsável por alfabetizá-las, criando um ambiente onde possam estar constantemente interagindo com os escritos, preparando-os para participar de uma sociedade letrada.

Quanto mais a criança interagir com textos escritos e indivíduos letrados, maiores serão suas possibilidades de construir conhecimentos diversos sobre a leitura e a escrita. $\mathrm{O}$ conhecimento origina-se numa ocasião natural ou espontâneo e possibilita que a criança construa hipóteses sobre a escrita, que consequentemente produzem formas próprias e criativas de ler e escrever (FERREIRO; TEBEROSKI, 1999).

Portanto, para uma aprendizagem satisfatória, é necessário o empenho do aluno pela leitura. O domínio desta atividade será alcançado através do contato com bons textos. Na sala de aula ele precisa ser incentivado a interagir com os escritos, sem medo de errar, pois isto faz parte da aprendizagem, precisa construir o seu raciocínio com produções que façam parte de sua vida, para que desta forma, tenha prazer pelo aprendizado da leitura e da escrita. 
Para que o docente consiga alcançar a meta de tornar seus alunos leitores independentes e que se comuniquem com êxito através dos textos que produzem, é preciso que conheçam os materiais de leitura. A sala de aula é o ambiente adequado para o contato com diferentes tipos de textos e para que entendam suas particularidades.

Desta forma, é papel do docente propiciar aos alunos materiais que os incentivem a se interessar pelas atividades de ler e escrever. Precisa também estar capacitado para enfrentar os problemas de dificuldade de aprendizagem, tentando solucioná-los. Com isso, possibilitará que seus alunos avancem e aos poucos desenvolvam o prazer de ler e escrever e reconheçam que estas habilidades são necessárias.

\section{CONCLUSÃO}

Por meio da realização deste artigo, concluí que é necessário realizar um trabalho diferenciado com as crianças que estão em processo de alfabetização, de construção de conhecimentos, de descobertas e de desenvolvimento de habilidades. Desta forma, este período se torna produtivo e enriquecedor, considerando que elas têm facilidade em aprender, e isto precisa ser visto como um aspecto positivo para se obter sucesso neste trabalho.

Desta forma, os conteúdos devem ser contextualizados com a realidade do educando para sua compreensão e trabalhados de forma prazerosa e lúdica, com atividades dinâmicas e desafiadoras. Possibilitar a interação com materiais escritos e diversos tipos de textos é favorecer a aprendizagem da linguagem escrita.

Portanto, faz-se necessário mudanças na prática pedagógica com o objetivo de alcançar níveis elevados de crianças alfabetizadas, que não somente saibam ler e escrever, mas que façam uso destas habilidades no meio social e com isso venham a ser leitoras, escritoras, produtoras. Estas mudanças devem partir da conscientização do docente de que o trabalho que realiza precisa ser constantemente renovado, buscando aperfeiçoamento de sua prática pedagógica.

\section{REFERÊNCIAS}

BRASIL, Secretaria de Educação Básica. Parâmetros Curriculares Nacionais: Língua Portuguesa. Secretaria de Estado de Educação, 2001.

CARVALHO, Marlene. Guia prático do alfabetizador. $1^{\text {a }}$ edição. São Paulo: Ática, 2010. Série Princípios 243.

FERREIRO, Emília. Reflexões sobre alfabetização. $20^{\text {a }}$ edição. São Paulo: Cortez Editora: Editora Autores Associados, 1992. (Coleção Polêmicas do Nosso Tempo, v. 17). 
. Com todas as letras. $4^{\mathrm{a}}$ edição. São Paulo: Cortez, 1993. (Biblioteca da Educação série 8 - Atualidades em educação - v. 2).

FERREIRO, Emília e TEBEROSKY, Ana. Psicogênese da Língua escrita. Porto Alegre: Artmed, 1999.

RUSSO, Maria de Fátima e VIAN, Maria Inês Aguiar. Alfabetização: um processo em construção. $2^{a}$ edição. São Paulo: Editora Saraiva, 1995.

SOARES, Magda Becker. Letramento: um tema em três gêneros. Belo Horizonte: Autêntica, 1998.

As condições sociais da leitura: uma reflexão em contraponto. In: Leitura: perspectivas interdisciplinares. ZILBERMAN, Regina \& SILVA, Ezequiel Theodoro da (orgs.). $5^{a}$ ed. São Paulo: Ática, 1999. 